\title{
The Anatomy of Dorsal Ramus Nerves and Its Implications in Lower Back Pain
}

\author{
Linqiu Zhou ${ }^{1}$, Carson D. Schneck ${ }^{2}$, Zhenhai Shao ${ }^{3}$ \\ ${ }^{1}$ Department of Rehabilitation Medicine, Jefferson Medical College, Thomas Jefferson University, Philadelphia, USA; ${ }^{2}$ Department \\ of Anatomy, Temple University School of Medicine, Philadelphia, USA; ${ }^{3}$ Department of Orthopedics, Zhujiang Hospital, Nanfang \\ Medical University, Guangzhou, China. \\ Email: linzhoumd@yahoo.com
}

Received February $27^{\text {th }}, 2012$; revised March $12^{\text {th }}, 2012$; accepted April $28^{\text {th }}, 2012$

\begin{abstract}
This article reviews the relationship between the spinal dorsal ramus system and low back pain, including the anatomy, clinical findings, pathogenesis and treatment of low back pain mediated by spinal dorsal ramus and zygapophysial (facet) joint syndrome. Each spinal dorsal ramus arises from the spinal nerve and then divides into a medial and lateral branch. The medial branch supplies the tissues from the midline to the zygapophysial joint line and innervates two to three adjacent zygapophysial joints and their related soft tissues. The lateral branch innervates the tissues lateral to the zygapophysial joint line. The clinical pain presentations follow these anatomic distributions, which can be used for localizing the involved dorsal ramus. The diagnosis can be confirmed by performing a single dorsal ramus block that results in relief of pain and muscle spasm. Etiologically, any factor that stimulates the spinal dorsal ramus can cause low back pain, which is distinct from zygapophysial joint syndrome. Clinically, L1 and L2 are the most common sites of dorsal rami involvement. Treatment includes spinal dorsal ramus injection therapy and percutaneous neurotomy. Summarily, irritation of the spinal dorsal ramus system is a potential source of low back pain. Based on the anatomy and clinical presentation, the involved spinal dorsal ramus can be localized and treated.
\end{abstract}

Keywords: Low Back Pain; Spinal Dorsal Ramus Syndrome; Medial Branch and Lateral Branch; Zygapophysial Joint; Spinal Dorsal Ramus Injection and Neurotomy

\section{Introduction}

The etiologies of low back pain are numerous. Anatomically, lumbar muscle strain [1,2], lumbar zygapophysial joint syndrome [3-11], instability of the lumbar spine [12], discogenic back pain [1,13], and sacroiliac joint syndrome [2] can cause low back pain. Mechanical pressure on the nerve roots, which may interfere with venous return of the nerve root [14], epidural fibrosis [15], perineural and intraneural fibrosis [16], are additional factors to consider. Additionally, some authors have suggested that the iliolumbar ligament inserting on the lumbar spine is a source of back pain [17]. These etiologies however do not account for all causes of low back pain.

Earlier literature has described irritation of the spinal dorsal ramus system as a cause of back pain [18]. Maigne implicated that low back pain was caused by irritating lateral branches of the spinal dorsal rami at the thoracolumbar region [19-22]. Anatomically, Bogduk's work exposed the medial branches of the lumbar spinal dorsal rami as a potential player in low back pain [23-25].
Sihvonen et al. blocked the medial dorsal ramus branch, which resulted in relief of muscle spasms and they suggested that this treatment would aid in improving lumbopelvic rhythm and reducing low back pain [26-29]. These studies supported spinal dorsal ramus as a potential pain generator.

The term "lumbar dorsal ramus syndrome" was created by Bogduk in 1980 [23], and was also described by Sihvonen in 1995 [28]. From their reports, "lumbar dorsal ramus syndrome" referred to low back pain caused by irritation of the medial branches of spinal dorsal ramus. However, this "lumbar dorsal ramus syndrome" could not tell the specific nerve level based on their articles. In this paper, we review the normal and pathological anatomy of the spinal dorsal ramus system and their relationship to the evaluation and treatment of low back pain syndromes.

\section{Spinal Dorsal Rami Anatomy of the Thoracolumbar Region (Figure 1)}

Thoracolumbar spinal dorsal rami anatomy is well de- 
scribed. The common dorsal ramus arises from the spinal nerve as it exits the neural (intervertebral) foramen [19, 20,24,30-39].

The common dorsal ramus passes dorsally and caudally, entering the back through an anatomic foramen bounded by the superior border of the transverse process, the anterior aspect of the superior articular zygapophysial joint, and the intertransverse ligament. Approximately five to ten millimeters from its origin, the common dorsal ramus divides at about a 30-degree angle into medial and lateral branches (Figures 1(a)-(d)). Both the medial and lateral branches contain sensory and motor fibers and are accompanied by blood vessels. The medial branch supplies the tissues from the midline to the zygapophysial

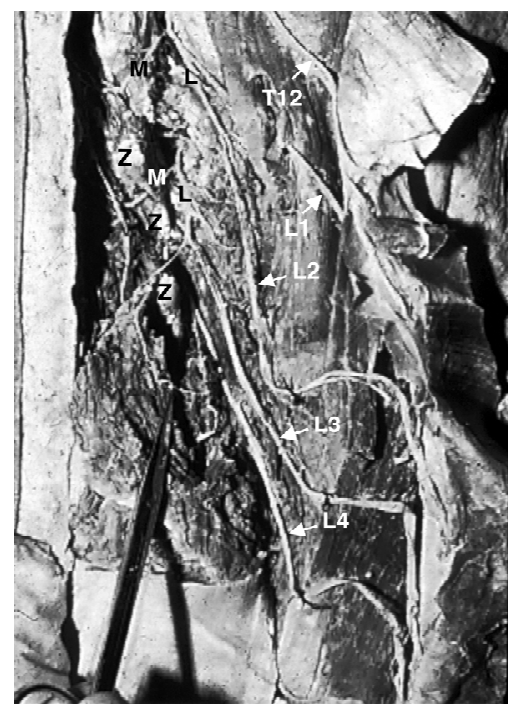

(a)

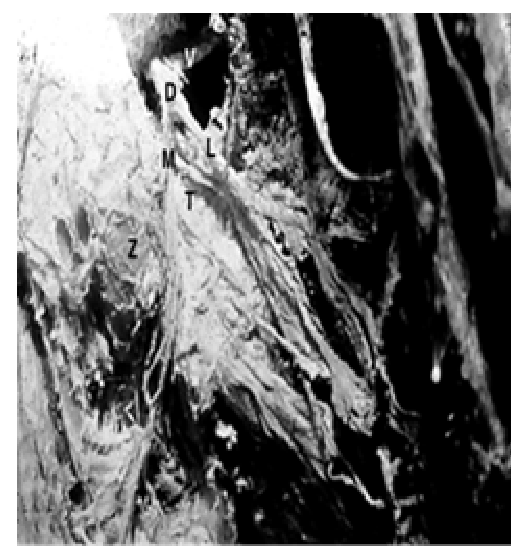

(c) joint line. The lateral branch innervates the tissues lateral to the zygapophysial joint line [36,39]. The L3 and L4 common dorsal rami (and sometimes the L1 and L2 common dorsal rami) give off intermediate branches, which run dorsally and caudally from the intertransverse spaces and supply the lumbar fibers of the longissimus thoracis [25]. Within the longissimus muscles, some of the intermediate branches of the L2 and L4 dorsal rami form an intersegmental communicating loop [25]. Steinke and his colleagues found that a short ventral intermediate branch from the common dorsal rami in the thoracolumbar region innervate the muscles between of the medial and lateral branch innervation [39].

The medial branch of dorsal rami, a smaller branch,

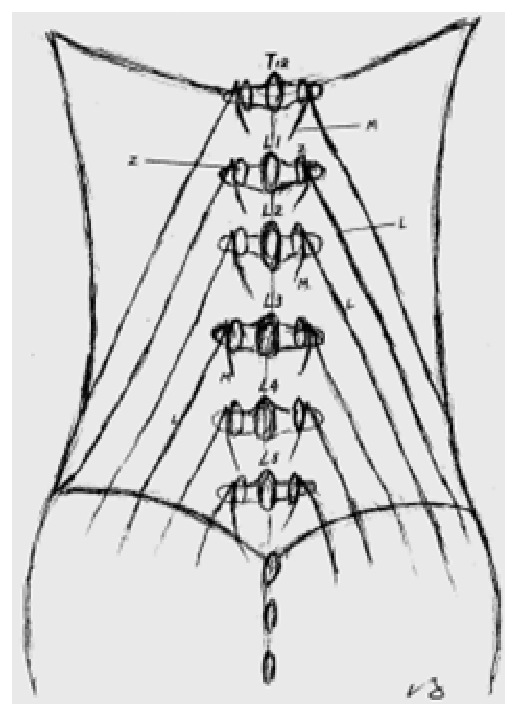

(b)

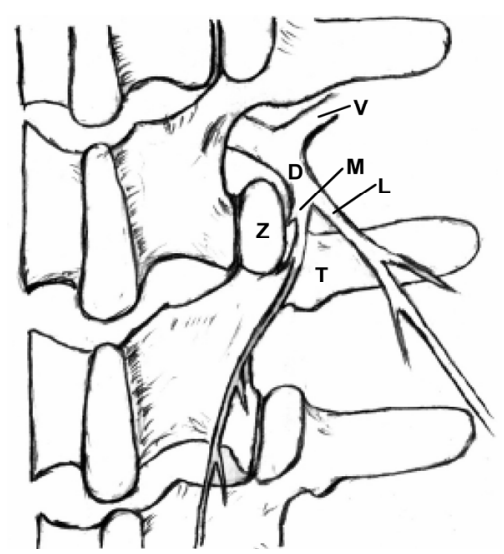

(d)

Figure 1. Dissection of the dorsal rami. (a) and (b) A posterior view of the right T12, L1, L2, L3 and L4 spinal dorsal rami nerves. The medial branches $(M)$ innervate the Zygapophysial (facet) joints $(Z)$ and the multifidus muscles medial to the zygapophysial joint line. The lateral branches $(\mathrm{L})$ innervate the longissimus and iliocostalis lateral to the zygapophysial joint line [38,39]. The T12 and $L 1$ branches terminate in the lateral gluteal region and the $L 2, L 3$ and $L 4$ branches terminate in the medial gluteal area; (c) A close up view of the common dorsal ramus (D) emerging from the neural foramen and dividing into medial (M) and lateral (L) branches at the upper margin of the transverse process (T). The medial branch then descends in the groove between the superior articular processes of the zygapophysial (facet) joint $(Z)$ and the root of the transverse process; (d) Illustration of the close up view of the common dorsal ramus. Ventral ramus (V). 
originates from the common dorsal ramus at or just outside of the intervertebral foramen. It passes the superior border of the transverse process and continues dorsally and caudally, lying in the groove formed by the junction of the transverse process and the lateral aspect of the superior articular process (Figures 1(c) and (d)), where it is covered by the mammilloaccessory ligament, that bridges between the mammillary and accessory processes of the lumbar lamina. A small nerve arising from the medial branch extends to the inferior aspect of the articular capsule, while the main medial branch continues across the lamina at the board of zygapophysial joint and extends caudally to 1 to 2 lower levels (Figures 1(a)-(d)). During its course, it gives branches to supply the zygapophysial joints and the mulitifidus muscles between the midline and the zygapophysial joint line $[28,39,40]$. The main branch passes dorsally and caudally to innervate the interspinous ligament and interspinal muscles [24,25, 34-38,41,42].

The lateral branch of dorsal ramus, a large branch, is approximately one millimeter in diameter $[19,21,22,25$, $31,35-37]$ and has a variable course. The nerve lies in an osseous groove of the superior transverse process. It then turns caudally, laterally, and dorsally under the longissimus muscles, and sends branches to the iliocostalis and longissimus muscles. After passing the iliocostalis muscle, the main lateral branch descends approximately two vertebral segments before it pierces the dorsal layer of the thoracolumbar fascia into the subcutaneous region and supplies skin. The lateral branches originating from T12 and L1 innervate the dermatome just below the lateral iliac crest and posterior to the anterior superior iliac, while the L2 and L3 lateral branches innervate the buttocks (Figures 1(a) and (b)). Distal anastomoses of lateral branches have been observed, particularly between the nerves of $\mathrm{T} 11$ and $\mathrm{T} 12, \mathrm{~T} 12$ and $\mathrm{L} 1$, and $\mathrm{L} 2$ and $\mathrm{L} 3$ $[19,21,22,25]$. The courses of the lateral branches of L4 and L5 are more variable. Maigne reported that there are no cutaneous branches of the L4 and L5 lateral branches in his 37 dissections [19]. Bogduk found that the L4 lateral branch remains intramuscularly [25]. The L5 lateral branch (typically communicates with S1 dorsal ramus and is therefore called communicating branch) originates from the L 5 common dorsal ramus at the caudal aspect of the lumbosacral junction $[24,25,37,38]$. It runs caudally to innervate the longissimus thoracis, which arise from the medial aspect of the dorsal segment of the iliac crest.

The distribution area of each dorsal ramus is characterized by an overlapping multiple segmental innervations, e.g., the L4 zygapophysial joint is innervated by the L3 and L4 medial branches. Therefore, if single dorsal ramus is irritated proximally, a patient could experience pain at the distal site of this nerve distribution (referred pain). This phenomenon mimics radicular pain, for example, a patient with L4-5 herniated disc experiences pain on his dorsal foot. Thus, a local anesthetic injected to the referred pain area will not relieve pain, because the pain is caused by irritation at the proximal dorsal ramus (see below) [36].

The medial and lateral branches divide at the junction of the lateral zygapophysial joint and the proximal superior border of the transverse process. The courses of the lateral branches are variable and commonly overlapping. There is no specific anatomic landmark to localize the lateral branches and the distal medial branches. Therefore, most physicians prefer to inject medication to the junction of the lateral zygapophysial joint and the proximal superior border of the transverse process to block the common dorsal ramus and its medial and lateral branches $[36,38,41,43]$.

\section{Clinical Presentation of Spinal Dorsal Nerve Mediated Back Pain}

Dr. Maigne has described the low back pain caused by the thoracolumbar lateral branches and called this pain as Thoracolumbar Junction Syndrome [19-22]. Dr. Bogduk pointed out that the medial branch of lumbar dorsal ramus may associate with low back pain [23-25,41]. As we all known, events precipitating low back pain include, but are not limited to, simple activities such as twisting, awkward positioning, bending, and lifting [44]. In patients with the spinal dorsal ramus mediated pain, their symptoms usually are on one side and are exacerbated by lumbar extension and/or rotation. This pain may radiate to the ipsilateral low back and buttock region (referred pain) [21,22] (Figure 2). Some patients may present paraspinal muscle spasm (Figure 3(a)). Hyperesthesia may present in the affected dermatome $[10,21,22,31,35$, $45,46]$.

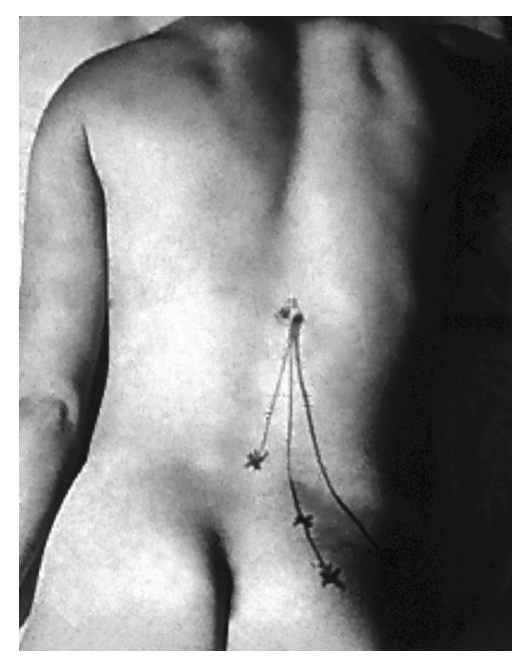

Figure 2. The common dorsal ramus involvement with the primary and referred pain (arrows). 
The pattern of lower back pain can be used to localize the irritated dorsal ramus or its branches based on the anatomy of spinal dorsal rami $[36,39,47]$. The zygapophysial joint line demarcates the distribution of the medial and lateral branches. Pain at between the midline and the zygapophysial joint line or the paraspinal sacroiliac region is caused by on irritated medial branch. Pain lateral to the zygapophysial joint line with radiation to the lateral iliac crest is induced by the lateral branch involvement $[19,22]$. When the common dorsal ramus is involved, pain will be at the territories of both medial and lateral branches [36,38,47] (Figure 2). There are some clinical findings in the patient with the spinal dorsal ramus mediated low back pain. The patient usually points to pain at the distal low back (referred pain) $[19,22,47]$. When the patient bends forward, there is usually a palpable step-off at the affected spinous processes and this is typically two to three segments above the referred pain [47]. There is a palpably widened space and deep tenderness between the spinous processes below the stepoff. With deep palpation of the junction of the same level lateral zygapophysial joint and proximal transverse process, the patient will experience pain and referred pain [19-22,36,47] (Figure 2). Additionally, patients may present an ipsilateral segmental muscle spasm, and a mild scoliosis at the affected vertebral level when the medial branch is involved (Figure 3(a)) [36,47]. If the lateral branch is involved, palpating the longissimus and the iliocostalis muscles can be painful [19-22,35,36,47]. Maigne's examination techniques are to provoke pain by applying pressure to the lateral aspect of the spinous processes and rubbing the ipislateral facet at the thoracolumbar junction [19-22]. Other findings such as motor, sensory and straight leg raising tests are unremarkable. When the low back pain patient presents pain with radiation below the knee and positive nerve root signs such as loss of sensory or motor function or reflexes in the distribution of the ventral ramus, the ventral ramus involvement (lumbar radiculopathy) should be considered [1].

During the acute phase of spinal dorsal ramus mediated back pain, the patient's radiographic imaging may show segmental vertebral rotation, asymmetrical zygapophysial joint spaces, mild scoliosis and double lines of the posterior vertebral body silhouette [21,22,48,49] (Figure 4) at the involved level. In some instances, a zygapophysial process fracture or vertebral body compression fracture may be revealed $[48,49]$. These imaging findings are not specific for spinal dorsal ramus mediated back pain. Therefore, it is very important to correlate these nonspecific radiographic findings with the clinical presentation.

At the physical exam's suspected level of involvement, a metal marker is put on the skin before the radiographic imaging study to identify the involved level (Figure 4(a)). Using fluoroscopic guidance, a diagnostic block can be performed, by injecting $2 \mathrm{ml}$ of $1 \%$ lidocaine to the junction of the lateral zygapophysial joint and the proximal superior transverse process (the location of the common dorsal rami) [20-22,36], (Figure 4(b)). During the procedure, placing the needle may reproduce the patient's symptoms, which further confirm accurate needle placement. A positive response is demonstrated by immediately relief of pain and segmental muscle spasm after the injection (Figure 3(b)).

\section{Pathogenesis}

The common dorsal ramus and its medial branch begin adjacent to the zygapophysial joint. Any abnormality of the zygapophysial joint such as vertebral malrotation or muscle spasm as well as structural changes of the zygapophysial joint such as subluxation, degeneration, bony

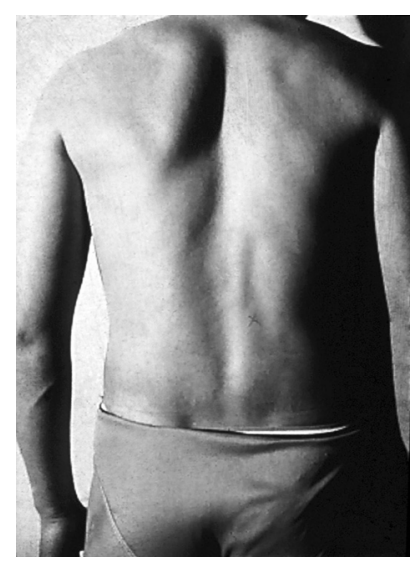

(a)

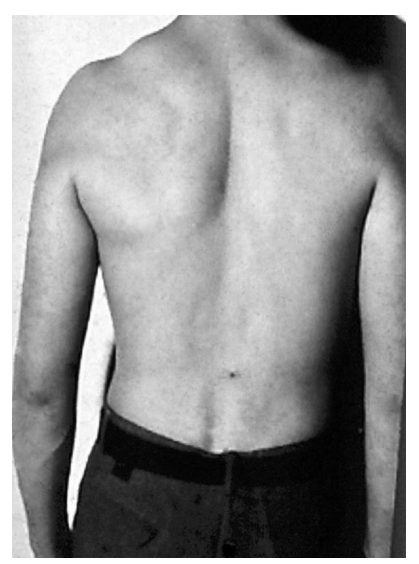

(b)
Figure 3. (a) Segmental muscle spasm and mild scoliosis at the involved level; (b) After dorsal ramus injection: the segmental muscle spasm and mild scoliosis resolved.

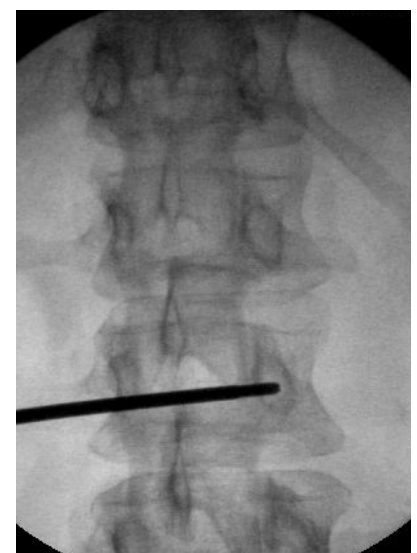

(a)

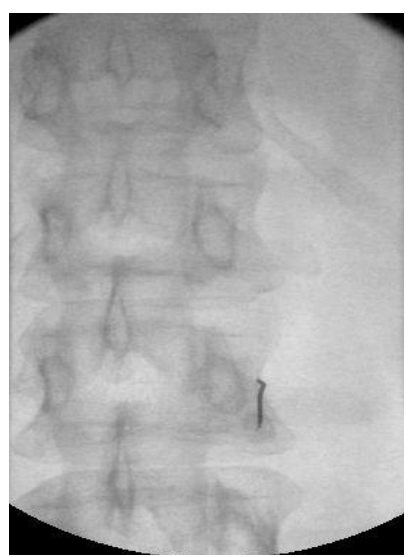

(b)
Figure 4. (a) A metal mark is used to confirm the involved level; (b) The needle position during the injection. 
proliferation, capsular/ligamentous hypertrophy or fracture can irritate the common dorsal ramus and medial branch, and induce clinical symptoms $[18,44,47,48]$. Ossification of the mammilloaccessory ligament may cause an entrapment neuropathy and low back pain $[18,24,33]$.

Biomechanical studies with fresh cadavers demonstrated that the upper lumbar zygapophysial joints carry a greater loading force than the lower zygapophysial joints [50]. Chen and colleagues [51] dissected the spinal dorsal rami from T12 to the sacrum and conducted biomechanical studies. Their study demonstrated that the L2 dorsal rami bore the greatest stretching force and tensile stress when the specimens were flexed and rotated to the contralateral side. Additionally, the radiographic changes including asymmetrical zygapophysial joint spaces and double shadow line at the posterior vertebral body silhouette were seen at the L2 level during the flexion and rotation studies. These imaging findings are similar to the radiographic findings from the patients, who have with spinal dorsal ramus mediated low back pain.

Spinal dorsal ramus mediated back pain can occur at any level of the human spine $[18,21,22,44,52,53]$. For low back pain mediated by dorsal ramus, the primary pain is commonly at the thoracolumbar junction [19-22, $38,44]$. Within the thoracic region, the coronal orientation of the zygapophysial joints grants spine free rotation. However, this rotation is limited by a rigid rib cage, except at the T10-12 levels because of floating ribs. The upper lumbar facets also have a relative coronal orientation. Therefore, spine rotation is relatively free at the thoracolumbar junction and the greatest shear force occurs at the more mobile upper lumbar segments. This normal spinal movement can cause zygapophysial joint separation or rotation. If these movements occur rapidly or overcome the body's physiological limit, they can cause stretching tension and irritation to the dorsal ramus, resulting in low back pain $[20,40,44,54]$. Shao and his colleagues reported that seventy four percent $(74 \%)$ of the 1263 patients with spinal dorsal ramus mediated low back pain had the pain originating from L1 and/or L2 dorsal ramus [36].

An electrophysiological abnormality may occur when the lumbar dorsal ramus is irritated. Somatosensory evoked potentials have shown a prolonged duration and decrease of amplitudes, when the spinal dorsal ramus is injured [55]. Electromyographic studies also demonstrated a polysegmental denervation in the lumbar medial paraspinal muscles at the lesion level and $1-3$ segmental levels below $[29,56]$.

\section{Spinal Dorsal Ramus Mediated Back Pain vs. Zygapophysial Joint Syndrome}

In the patient with spinal dorsal ramus mediated back pain, the involved spinal dorsal ramus is typically two or three segments above referred pain. Dreyfuss and his colleagues injected contrast medium into the thoracic zygapophysial joints and induced patient's back pain, which radiated to 2 - 3 segments below the injected site [57]. The authors suggested that the referred pain was caused by the zygapophysial joint dilation after injection [57]. The explanation of this phenomena is that the distended joint capsular may irritate the medial branch or/ and common dorsal ramus, which are crossing the zygapophysial joint, and cause the referred pain.

The major differential diagnosis of spinal dorsal ramus mediated back pain is zygapophysial joint syndrome [5,9, $45,58]$. The diagnosis of zygapophysial joint syndrome has been debated over past several decades $[59,60]$. There are no specific clinical criteria that are diagnostic of zygapophysial joint syndrome [61,62]. The final diagnosis relies on pain relief after zygapophysial joint injection [63-65]. On the other hand, the patient with spinal dorsal ramus mediated low back pain presents the clinical features described above. Nevertheless, the clinical presentations of zygapophysial joint syndrome and spinal dorsal ramus mediated low back pain may be similar. However, there are some distinguishing features between these two syndromes (Table 1):

1) Spinal dorsal ramus mediated low back pain can be caused by a number of biomechanical and neuroanatomical etiology, and is caused by spinal dorsal ramus irritation. Conversely, zygapophysial joint syndrome is caused by facet joint pathology $[4,9,45]$.

2) The thoracolumbar junction is the most common site of spinal dorsal ramus mediated low back pain [19$22,36,44]$; while, zygapophysial joint syndrome commonly occurs at the lower lumbar segments such as L5S1, L4-5 and L3-4 [5,6,9,43,64,66].

3) Patients with spinal dorsal ramus mediated low back pain present pain at low back, but their primary pain is at upper low back, 2 - 3 levels above the referred pain. Additionally, in the acute phase, the patients also present paraspinal muscle spasm. However, patients with zygapophysial joint syndrome present pain at the level of zygapophysial joint disease $[45,58]$.

4) The clinical findings of spinal dorsal ramus mediated low back pain are a palpable step-off of the spinous process and a widened interval between the spinous processes[47], that is also tender [19-22]. It also presents a deep tenderness at the junction of the lateral zygapophysial joint and superior proximal transverse process with referred pain [19-22,47]. The patient with zygapophysial joint syndrome normally shows tenderness at the involved zygapophysial joints $[58,61]$.

5) The diagnostic injection site for the patient with spinal dorsal ramus mediated low back pain usually is a single dorsal ramus $[21,22,27,47]$. In comparison, the 
Table 1. Differential diagnoses of spinal dorsal ramus mediated low back pain vs. zygapophysial joint syndrome.

\begin{tabular}{|c|c|c|}
\hline & Spinal Dorsal Ramus Mediated Back Pain & Zygapophysial Joint Syndrome \\
\hline Pathogenesis & Neuroanatomical disorder & Zygapophysial joint pathology \\
\hline Pain & $\begin{array}{l}\text { Pain is following anatomic distribution; the primary pain is at two to } \\
\text { three segments above referred pain, commonly at L1 and L } 2\end{array}$ & $\begin{array}{l}\text { Pain is at the same level of pathology, } \\
\text { common at L5-S1, L4-5 and L3-4 } \\
\text { zygapophysial joints }\end{array}$ \\
\hline Physical examination & $\begin{array}{l}\text { Protuberance of the spinal process; widened interspinous processe } \\
\text { space; tenderness at the spinous process and the junction of the lateral } \\
\text { zygapophysial joint and proximal transverse process, with referred } \\
\text { pain to the clinical painful site }\end{array}$ & $\begin{array}{l}\text { Zygapophysial joint tenderness, pain is } \\
\text { aggravated by lumbar extension }\end{array}$ \\
\hline Confirming injection & Single dorsal ramus injection & $\begin{array}{l}\text { Single or multiple zygapophysial joint } \\
\text { injections }\end{array}$ \\
\hline Definitive therapy & Neurotomy of single dorsal ramus & $\begin{array}{l}\text { Neurotomy of single or multi-level } \\
\text { medial branch(es) of dorsal rami }\end{array}$ \\
\hline
\end{tabular}

diagnostic injection for the patient with zygapophysial joint syndrome requires single or multiple zygapophysial joints, versus single or multiple dorsal rami, commonly at L5-S1, L4-5 and L3-4 levels [7,58,61,64,66,67].

6) Finally, neuroablation therapy for patients with spinal dorsal ramus mediated low back pain typically involves a single dorsal ramus $[21,22,47]$. The patient with zygapophysial joint syndrome requires single or multiple dorsal rami radiofrequency neurolysis [58,61,64,66,67].

\section{Treatment}

In the past two decades, spinal dorsal ramus blocks and dorsal ramus denervation with radiofrequency or surgical procedures have become popular procedure in the treatment of low back pain [3,5,42,66-68]. However, positive results are variable $[5,8,9,43,69,70]$. Here, we review the treatment of spinal dorsal ramus mediated back pain.

\subsection{Spinal Dorsal Ramus Injection}

There has been a long-term debate on the role of steroids and local anesthesia injection in treatment of back pain. A variety of targets including the epidural space, zygapophysial joint space, joint capsule and medial branches of the dorsal rami have been suggested. One of the major problems lies in determining which dorsal ramus (level) is causing symptoms [71]. To avoid this issue, some authors have injected multiple medial branches [24,64], or used a large volume of medication to cover multiple dorsal rami [43], in order to achieve a positive clinical outcome.

The techniques of the lumbar medial branch blocks have been well established [23-25,61]. The targeting point of injection is at the junction of lateral articular process and the proximal transverse process, where the nerve crosses [72]. The injecting sites for zygapophysial joint syndrome normally are at lower lumbar spine ( $\mathrm{S} 1$, L5, L4). The results of these injections in the double blind studies have been marginal at best [5,8,10,64,65]. The efficacy of these various injections ranges between $6 \%-68 \%$. Sihvonen et al. reported that 21 patients with low back pain, who were treated with selective lumbar spinal dorsal rami injection, were pain free from 2 days to 12 months [28]. His study suggested that precisely locating these involved nerves was responsible for the good outcome.

The target of treating spinal dorsal ramus mediated low back pain is the common dorsal ramus, which is located at the junction of the lateral zygapophysial joint and superior proximal transverse process (Figure 4(b)). The procedure is under the fluoroscopic guidance. When the tip of needle reaches to the involved spinal dorsal ramus, patients will experience a similar referred pain (radiating to the painful area). Patients typically experience instant pain relief immediately following the injection (Figure 3(b)). Shao reported that 120 patients with spinal dorsal ramus mediated low back pain were randomly divided into two equal groups [36]. The first group received an injection of the involved dorsal ramus (under the fluoroscopic guidance) and the second group received an injection at the referred painful site (complaining painful area). Patients in both groups were injected with $2 \mathrm{ml}$ of $2 \%$ lidocaine without epinephrine. In the first group, all patients achieved immediate pain reduction with the duration of pain relief from one hour to 23.25 hours (average of 6.42 hours). In the second group, 16 patients had no pain relief and 44 patients experienced ten minutes to one hour of pain relief (average 0.73 hours) [36]. Similar result was also reported by Chen in 1994 [73]. These studies suggested that accurate injection of the selective spinal dorsal ramus can provide both diagnostic and therapeutic purposes; while injection to the referred painful site is no beneficial [36]. Additionally, Zhou has reported in his retrospective study, that in 41 patients with spinal dorsal ramus mediated lower back pain, after the selective spinal dorsal ramus injection, 
$84 \%$ of these patients received greater than $50 \%$ and more than two months of pain reduction [74]. These patients also reported improvement in their daily activities and decrease of their pain medications [74].

\subsection{Spinal Dorsal Rami Neurotomy}

Medial branch neurotomy and facet denervation with radiofrequency [41,66,67], cryogenic lesion apparatus $[47,75,76]$ and surgically nerve denervation [20] have been reported in the past several decades. The medial branches radiofrequency neurotomy is indicated for patients who experienced more than $50 \%$ of pain relief after the medial branch blocks [66-68,77]. For facet joint syndrome patients, physicians normally prefer to ablate several medial branches (commonly at S1, L5 and L4), because the zygapophyzial joints are innervated by two to three medial branches from the different levels. Results of this therapy are variable from $17 \%$ to $87 \%$ pain relief $[68,69]$. However, in rigorously selected patients and with correct needle position, this procedure yielded an $85 \%$ $90 \%$ of successful rate either with cryo or radiofrequency neurotomy [78]. The duration of pain-relief after radiofrequency is from 6 months to 1 year [78]. The technique of dorsal ramus neurotomy for patients with spinal dorsal ramus mediated low back pain is similar to medial branch neurotomy except the targeting nerve is the common dorsal ramus. In Shao's retrospective study of 1997 cases of spinal dorsal ramus mediated low back pain, 1742 (87.2\%) patients experienced immediate pain relief and restored their normal lumbar motion after cryonueroablation [47]. In those 1742 patients, 409 were followed for an average of 2.5 years. Three hundred and eighty-six (94.3\%) of these 409 patients achieved long- lasting pain relief and returned to their occupation [47]. The complications of radiofrequency and cryotherapy are generally low, and include injection site pain, and neuritis, ranging from $1 \%$ to $6.5 \%$ [79]. There are no studies of long-term complications after radiofrequency and cryotherapy, including Charcot's joints. However, a recent study has shown that neurotomy of lumbar medial branches can cause muscle atrophy [80].

\section{Summary}

The dysfunction of lumbar dorsal ramus system is an important factor in low back pain. In the general population of patients with low back pain, the incidence of lumbar dorsal ramus mediated low back pain is not known. Lumbar spinal dorsal ramus mediated low back pain should be considered based on the anatomical and pain pattern. A thorough medical history and examination can help to localize the pathologic level. Normally, this type of pain originates at L1 or L2 dorsal rami, and the pathogeneses can be multiple factors which irritate the dorsal ramus. The back pain induced by dorsal ramus irritation can occur in the cervical [51] and thoracic spine [50] as well. Therefore, spinal dorsal ramus mediated back pain should be appropriately called "spinal dorsal ramus syndrome (SDRS)".

The key point is how to localize the involved dorsal ramus. The dorsal ramus can be irritated anywhere from the common dorsal ramus to its medial or lateral branches. The clinical presentations of dorsal ramus mediated back pain and zygapophysial syndrome can be overlapping. However, there are some distinctions. The thoracolumbar junction is the most common site of spinal dorsal ramus mediated back pain $[21,22,36]$, while, zygapophysial joint syndrome commonly occurs at the lower lumbar zygapophysial joints such as L5-S1 and L4-5 [5,6,9,43,57, 58].

There are no specific imaging findings to distinguish spinal dorsal ramus mediated back pain and zygapophysial joint syndrome [47,62]. The only confirming diagnostic test is a dorsal ramus vs. zygapophysial joint injection. Thus far, no double blind studies have confirmed the efficacy of these diagnostic tests. Spinal dorsal ramus mediated back pain can co-exist with zygapophysial joint syndrome and other causes of low back pain. Further clinical, anatomic, radiographic, and electrophysiological studies for spinal dorsal ramus mediated back pain are necessary. Randomized controlled studies of injecting spinal dorsal ramus vs. zygapophysial joint are essential to confirm their clinic value in diagnosis and treatment of low back pain.

\section{Acknowledgements}

This study was supported by the Natural Science Foundation of China (38807783, 39170731).

\section{REFERENCES}

[1] A. L. Nachemson, "Newest Knowledge of Low Back Pain: A Critical Look," Clinical Orthopaedics and Related Research, Vol. 279, 1992, pp. 8-20.

[2] T. N. Bernard and J. D. Cassidy, "The Sacroiliac Joint Syndrome: Pathophysiology, Diagnosis and Management," In: J. W. Frymoyer, Ed., The Adult Spine: Principles and Practice, Raven Press, New York, 1991, pp. 2107-2130.

[3] N. Bogduk, "International Spinal Injection Society Guidelines for the Performance of Spinal Injection Procedures: Part 1: Zygapophysial Joint Blocks," Clinical Journal of Pain, Vol. 13, No. 4, 1997, pp. 285-302. doi:10.1097/00002508-199712000-00003

[4] N. Bogduk and L. R. Enge, "The Menisci of the Lumbar Zygapophysial Joints: A Review of Their Anatomy and Clinical Significance," Spine, Vol. 9, No. 5, 1984, pp. 454-460. doi:10.1097/00007632-198407000-00006

[5] S. J. Dreyer and P. H. Dreyfuss, "Low Back Pain and the Zygapophysial (Facet) Joints," Archives of Physical Medi- 
cine and Rehabilitation, Vol. 77, No. 3, 1996, pp. 290300. doi:10.1016/S0003-9993(96)90115-X

[6] L. G. F. Giles and J. R. Taylor, "Innervation of Lumbar Zygapophysial Joint Synovial Folds," Acta Orthopaedica Scandinavica, Vol. 58, No. 1, 1987, pp. 43-46.

[7] G. Lilius, E. M. Laasonen, P. Myllynen, A. Harilainen and G. Gronlund, "Lumbar Facet Joint Syndrome: A Randomized Clinical Trial," Journal of Bone \& Joint Surgery, Vol. 71, No. 4, 1989, pp. 681-684.

[8] R. C. Marks, T. Houston and T. Thulbourne, "Facet Joint Injection and Facet Nerve Block: A Randomized Comparison in 86 Patients with Chronic Low Back Pain," Pain, Vol. 49, No. 3, 1992, pp. 325-328. doi:10.1016/0304-3959(92)90239-8

[9] V. Mooney and J. Robertson, "The Facet Syndrome," Clinical Orthopaedics and Related Research, Vol. 115, 1976, pp. 149-156.

[10] T. P. Nash, "Facet Joints-Intra-Articular Steroids for Nerve Block?" Pain Clinical, Vol. 3, No. 2, 1990, pp. 7782.

[11] A. C. Schwarzer, S. C. Wang, N. Bogduk, P. J. McNaught and R. Laurent, "Prevalence and Clinical Features of Lumbar Zygapophysial Joint Pain: A Study in an Australian Population with Chronic Low Back Pain," Annals of the Rheumatic Diseases, Vol. 54, No. 2, 1995, pp. 100106. doi:10.1136/ard.54.2.100

[12] T. Sihvonen, K. A. Lindgren, O. Airaksinen and H. Manninen, "Movement Disturbances of the Lumbar Spine and Abnormal Back Muscle Electromyographic Findings in Recurrent Low Back Pain," Spine, Vol. 22, No. 3, 1997, pp. 289-295. doi:10.1097/00007632-199702010-00012

[13] M. F. Brown, M. V. Hukkanen, I. D. McCarthy, D. R. Redfern, J. J. Batten, H. V. Crock, S. P. Hughes and J. M. Polak, "Sensory and Sympathetic Innervation of the Vertebral Endplate in Patients with Degenerative Disc Disease," Journal of Bone and Joint Surgery, Vol. 79, No. 1, 1997, pp. 147-153.

[14] J. M. Cavanaugh, A. C. Ozaktay, T. Yamashita, A. Avramov, T. V. Getchell and A. I. King, "Mechanism of Low Back Pain: A Neurophysiologic and Neuroanatomic Study," Clinical Orthopaedics and Related Research, Vol. 335, 1997, pp. 166-180.

[15] J. Richardson, P. McGurgan, S. Cheema, R. Prasad and S. Gupta, "Spinal Endoscopy in Chronic Low Back Pain with Radiculopathy: A Prospective Case Series," Anaesthesia, Vol. 56, No. 5, 2001, pp. 454-460. doi:10.1046/j.1365-2044.2001.01524-3.X

[16] K. Ido and H. Urushidani, "Fibrous Adhesive Entrapment of Lumbosacral Nerve Roots as a Cause of Sciatica," Spine Cord, Vol. 39, No. 5, 2001, pp. 269-273. doi:10.1038/sj.sc.3101157

[17] V. Rucco, P. T. Basadonna and D. Gasparini, "Anatomy of the Iliolumbar Ligament: A Review of Its Anatomy and a Magnetic Resonance Study," American Journal of Physical Medicine \& Rehabilitation, Vol. 75, No. 6, 1996, pp. 451-455. doi:10.1097/00002060-199611000-00010

[18] G. Lazorthes, "Le Syndrome de la Brancke Posterieure des Nerfs Spinaux, ” Press Medicalte, Vol. 62, 1956, p.
2022.

[19] J. Y. Maigne, J. P. Lazareth, H. G. Surville and R. Maigne, "The Lateral Cutaneous Branches of the Dorsal Rami of the Thoraco-Lumbar Junction," Surgical and Radiologic Anatomy, Vol. 11, No. 4, 1989, pp. 289-293. doi:10.1007/BF02098698

[20] R. Mainge, "Low Back Pain of Thoracolumbar Origin," Archives of Physical Medicine and Rehabilitation, Vol. 61, No. 9, 1980, pp. 389-395.

[21] R. Maigne, "Thoracolumbar Junction Syndrome, a Source of Diagnostic Errors," 2012.

http://www.maitrise-orthop.com/corpusmaitri/orthopaedic /mo70_maigne_thoracolumbar/index.shtml

[22] J. Y. Maigne, "Thoracolumbar Junction and Thoracolumbar Spinal Pain Syndromes," 2012.

http://www.sofmmoo.com/english_section/4_thoracolum bar_junction/thoracolumbar_junction_australie.htm

[23] N. Bodguk, "Lumbar Dorsal Ramus Syndrome," Medical Journal of Australia, Vol. 2, No. 10, 1980, pp. 537-541.

[24] N. Bogduk and D. M. Long, "The Anatomy of the SoCalled 'Articular Nerve' and Their Relationship to Facet Denervation in the Treatment of Low-Back Pain," Journal of Neurosurgery, Vol. 51, No. 2, 1979, pp. 172-177. doi:10.3171/jns.1979.51.2.0172

[25] N. Bogduk, A. S. Wilson and W. Tynan, "The Human Lumbar Dorsal Rami," Journal of Anatomy, Vol. 134, No. 2, 1982, pp. 383-397.

[26] T. Sihvonen, “The Segmental Dorsal Ramus Neuropathy as a Common Cause of Chronic and Recurrent Low Back Pain," Electromyography and Clinical Neurophysiology, Vol. 32, No. 10-11, 1992, pp. 507-510.

[27] T. Sihvonen, A. Herno, L. Paljärvi, O. Airaksinen, J. Partanen and A. Tapaninaho, "Local Denervation Atrophy of Paraspinal Muscles in Postoperative Failed Back Syndrome," Spine, Vol. 18, No. 5, 1993, pp. 575-581. doi:10.1097/00007632-199304000-00009

[28] T. Sihvonen, K. A. Lindgren, O. Airaksinen, E. Leino, J. Partanen and O. Hanninen, "Dorsal Ramus Irritation Associated with Recurrent Low Back Pain and Its Relief with Local Anesthesia or Training Therapy," Journal of Spinal Disorders, Vol. 8, No. 1, 1995, pp. 8-14. doi:10.1097/00002517-199502000-00002

[29] T. Sihvonen, J. Partenen, O. Hanuman and S. Soimakallio, "Electric Behavior of Low Back Muscles during Lumbar Pelvic Rhythm in Low Back Pain Patients and Healthy Controls," Archives of Physical Medicine and Rehabilitation, Vol. 72, No. 13, 1991, pp. 1080-1087.

[30] S. Fukui, K. Ohseto, M. Shiotani, K. Ohno, H. Karasawa and Y. Naganuma, "Distribution of Referred Pain from the Lumbar Zygapophyseal Joints and Dorsal Rami," Clinical Journal of Pain, Vol. 13, No. 4, 1997, 303-307. doi:10.1097/00002508-199712000-00007

[31] J. Y. Maigne and R. Maigne, "Trigger Point of the Posterior Iliac Crest: Painful Iliolumbar Ligament Insertion or Cutaneous Dorsal Ramus Pain? An Anatomic Study," Archives of Physical Medicine and Rehabilitation, Vol. 72, No. 10, 1991, pp. 734-737.

[32] M. Masini, W. S. Paiva and A. S. Araujo Jr., "Anatomical 
Description of the Facet Joint Innervation and Its Implication in the Treatment of Recurrent Back Pain," Journal of Neurosurgical Sciences, Vol. 49, No. 4, 2005, pp. 143146.

[33] S. V. Paris, "Anatomy as Related to Function and Pain," Orthopedic Clinics of North America, Vol. 14, No. 3, 1983, pp. 475-489.

[34] H. E. Pedersen, C. F. J. Blunck and E. Gardner, "The Anatomy of Lumbosacral Posterior Rami and Meningeal Branches of Spinal Nerves (Sinu-Vertebral Nerves)," Journal of Bone \& Joint Surgery, Vol. 38, No. 2, 1956, pp. 377-391.

[35] Z. Shao, Z. Chen, L. Zhou, A. Jin and Q. Li, "Spinal Dorsal Ramus Syndrome," Chinese Medical Journal, Vol. 109, No. 4, 1996, pp. 317-321.

[36] Z. H. Shao, A. M. Jim, L. Q. Zhou, Q. Zhong and L. X. Zhu, "Posterior Spinal Rami in Localization of Low Back Pain," Chinese Journal of Surgery, Vol. 30, No. 4, 1992, pp. 205-206.

[37] Z. H. Shao and H. J. Wu, "Dorsal Ramus Blockage: Clinical Application and Anatomical Basis," Academic Journal of the First Medical University of PLA, Vol. 6, No. 4, 1986, pp. 291-292.

[38] S. N. Tang, Z. H. Shao and Y. M. Hu, "Applied Anatomy of the Dorsal Rami of Lumbar Spinal Nerves for Cryotherapy of Lumbago," Chinese Journal of Clinical Anatomy, Vol. 10, No. 1, 1992, pp. 18-20.

[39] H. Steinke, T. Saito, T. Miyaki, Y. Oi, M. Itoh and K. Spanel-Borowski, "Anatomy of the Human Thoracolumbar Rami Dorsales Nervi Spinalis," Annals of AnatomyAnatomischer Anzeiger, Vol. 191, No. 4, 2009, pp. 408416. doi:10.1016/j.aanat.2009.04.002

[40] J. Y. Maigne, X. Ayal and H. Guerin-Surville, "Frequency and Size of Ossifications in the Caudal Attachments of the Ligamentum Flavum of the Thoracic Spine: Role of Rotatory Strains in Their Development (An Anatomic Study of 121 Spines)," Surgical and Radiologic Anatomy, Vol. 4, No. 2, 1992, pp. 119-124. doi:10.1007/BF01794886

[41] N. Bogduk and D. M. Long, "Percutaneous Lumbar Medial Branch Neurotomy. A Modification of Facet Denervation," Spine, Vol. 5, No. 2, 1980, pp. 193-200. doi:10.1097/00007632-198003000-00015

[42] Z. H. Shao, "Cryotherapy of Deep Tissue: A New Technique in Orthopedics," Journal of Medical Colleges of PLA, Vol. 13, No. 5, 1988, pp. 332-334.

[43] N. Miyakoshi, Y. Shimada, Y. Kasukawa, H. Saito, H. Kodama and E. Itoi, "Total Dorsal Ramus Block for the Treatment of Chronic Low Back Pain: A Preliminary Study," Joint Bone Spine, Vol. 74, No. 3, 2007, pp. 270274. doi:10.1016/j.jbspin.2006.07.006

[44] J. D. Fortin, "Thoracolumbar Syndrome in Athletes: A Case Report," Pain Physician, Vol. 6, 2003, pp. 373-375.

[45] S. M. Eisenstein and C. R. Parry, "The Lumbar Facet Arthrosis Syndrome, Clinical Presentation and Articular Surface Changes," Journal of Bone and Joint Surgery, Vol. 69, No. 1, 1987, pp. 3-7.

[46] S. I. Nakamura, K. Takahashi, Y. Takahashi, M. Yama- gata and H. Moriya, "The Afferent Pathways of Discogenic Low-Back Pain: Evaluation of L2 Spinal Nerve Infiltration," Journal of Bone \& Joint Surgery, Vol. 78, No. 4, 1996, pp. 606-612.

[47] Z. H. Shao, L. Q. Zhou, X. Q. Shu, A. M. Jim and Q. Zhong, "Cryotherapy for Low-Back Pain," Chinese Journal of Surgery, Vol. 29, No. 12, 1991, pp. 721-723.

[48] Z. H. Shao, Z. Chen, A. M. Jin, Q. Li and X. Y. Zhou, "Spinal Dorsal Ramus Syndrome," Orthopedic Journal of China, Vol. 9, No. 6, 2002, pp. 611-612.

[49] L. X. Zhu and Z. H. Shao, "The Lumbar Spine X-Ray Studies of Low Back Pain," in Chinese, Journal of Cervicolumbago, Vol. 173, 1996, pp. 191-192.

[50] M. Lorenz, A. Patwardhan and R. Vanderby Jr., "LoadBearing Characteristics of Lumbar Facets in Normal and Surgically Altered Spinal Segments," Spine, Vol. 8, No. 2, 1983, pp. 122-130. doi:10.1097/00007632-198303000-00002

[51] Z. S. Chen, Z. H. Shao, X. A. Zhu and S. Z. Zhong, "Anatomic and Bio-Mechanism Studies for Posterior Ramus' Low Back Pain," in Chinese, Journal of Bone and Joint Trauma, Vol. 9, 1994, pp. 116-118.

[52] J. Y. Maigne, R. Maigne and H. Guerin-Surville, "Upper Thoracic Dorsal Rami: Anatomic Study of Their Medial Cutaneous Branches," Surgical and Radiologic Anatomy, Vol. 13, No. 2, 1991, pp. 109-112. doi:10.1007/BF01623882

[53] L. Q. Zhou, Z. H. Shao, A. M. Jin, X. Q. Shu and Q. Zhong, "Cryoanalgesia for Cervicoscapulagia," in Chinese, Journal of Cervicolumbago, Vol. 15, No. 2, 1994, pp. 85-86.

[54] K. P. Singer, R. E. Day and P. D. Breidahl, "In Vivo Axial Rotation at the Thoracolumbar Junction: An Investigation Using Low Dose CT in Healthy Male Volunteers," Clinical Biomechanics, Vol. 4, No. 3, 1989, pp. 145-150. doi:10.1016/0268-0033(89)90017-X

[55] Y. Zhu, S. Haldeman, A. Starr, M. A. Seffinger and S. H. $\mathrm{Su}$, "Paraspinal Muscle Evoked Cerebral Potentials in Patients with Unilateral Low Back Pain," Spine, Vol. 18, No. 8, 1993, pp. 1096-1102. doi:10.1097/00007632-199306150-00022

[56] A. J. Haig, K. Yamakawa and D. M. Hudson, "Paraspinal Electromyography in High Lumbar and Thoracic Lesion," American Journal of Physical Medicine \& Rehabilitation, Vol. 79, No. 4, 2000, pp. 336-342. doi:10.1097/00002060-200007000-00004

[57] P. Dreyfuss, C. Tibitetti and S. J. Dreyer, "Thoracic Zygapophysial Joint Pain Patterns: A Study in Normal Volunteers," Spine, Vol. 19, No. 7, 1994, pp. 807-811. doi:10.1097/00007632-199404000-00014

[58] D. C. Manning and J. C. Rowlingson, "Back Pain and the Role of Neural Blockade," In: M. J. Cousins and P. O. Bridenbaugh, Eds., Neural Blockade: In Clinical Anesthesia and Management of Pain, Lippincott-Raven, Philadelphia, 1998, pp. 879-914.

[59] A. C. Schwarzer, C. N. Aprill, R. Derby, J. Fortin, G. Kine and N. Bogduk, "Clinical Features of Patients with Pain Stemming from the Lumbar Zygapophysial Joints. Is 
the Lumbar Facet Syndrome a Clinical Entity?" Spine, Vol. 19, No. 10, 1994, pp. 1132-1137. doi:10.1097/00007632-199405001-00006

[60] R. P. Jackson, "The Facet Syndrome. Myth or Reality?" Clinical Orthopaedics and Related Research, Vol. 279, 1992, pp. 110-121.

[61] J. L. Pappas, C. H. Kahn and C. A. Warfield, "Facet Block and Neurolysis," In: W. Waldman, Ed., Interventional Pain Management, Dannemiller Memorial Educational Foundation, Philadelphia, 1996, pp. 284-303.

[62] Z. M. Beresford, R. W. Kendall and S. E. Willick, "Lumbar Facet Syndromes," Current Sports Medicine Reports, Vol. 9, No. 1, 2010, pp. 50-56.

[63] V. Mark, M. V. Boswell, A. Trescot, S. Datta, D. M. Schultz, et al., "Interventional Techniques: EvidenceBased Practice Guidelines in the Management of Chronic Spinal Pain," Pain Physician, Vol. 10, No. 1, 2007, pp. 7-111.

[64] N. Sehgal, E. E. Dunbar, R. V. Shah and J. Colson, "Systematic Review of Diagnostic Utility Of Facet (Zygapophysial) Joint Injections in Chronic Spinal Pain: An Update," Pain Physician, Vol. 10, No. 1, 2007, pp. 213228.

[65] N. Bogduk, "On Diagnostic Blocks for Lumbar Zygapophysial Joint Pain," F1000 Medicine Reports, Vol. 2, 2010, p. 57. doi:10.3410/M2-57

[66] M. van Kleef, G. A. Barendse, A. Kessels, H. M. Voets, W. E. Weber and S. de Lange, "Randomized Trial of Radiofrequency Lumbar Facet Denervation for Chronic Low Back Pain," Spine, Vol. 24, No. 18, 1999, pp. 1937-1942. doi:10.1097/00007632-199909150-00013

[67] W. M. Hooten, D. P. Martin and M. A. Huntoon, "Radiofrequency Neurotomy for Low Back Pain: EvidenceBased Procedural Guidelines," Pain Medicine, Vol. 6, No. 2, 2005, pp. 129-138. doi:10.1111/j.1526-4637.2005.05022.x

[68] R. B. North, M. Han, M. Zahurak and D. H. Kidd, "Radiofrequency Lumbar Facet Denervation: Analysis of Prognostic Factors," Pain, Vol. 57, No. 1, 1994, pp. 7783. doi:10.1016/0304-3959(94)90110-4

[69] N. Bogduk and J. Dreyfuss, "A Narrative Review of Lumbar Medial Branch Neurotomy for the Treatment of Back Pain," Pain Medicine, Vol. 10, No. 6, 2009, pp. 1035-1045. doi:10.1111/j.1526-4637.2009.00692.x

[70] N. Bogduk, "Narrative Review of Intra-Articular Corticosteroid Injections for Low Back Pain," Pain Medicine,
Vol. 6, No. 4, 2005, pp. 287-296. doi:10.1111/j.1526-4637.2005.00048.x

[71] R. J. Stolker, A. C. Vervest, L. M. Ramos and G. J. Groen, "Electrode Positioning in the Thoracic Percutaneous Partial Rhizotomy: An Anatomical Study," Pain, Vol. 57, No. 2, 1994, pp. 241-251. doi:10.1016/0304-3959(94)90229-1

[72] N. Bogduk, "International Spinal Injection Society Guidelines for the Performance of Spinal Injection Procedures: Part 1: Zygapophysial Joint Blocks," Clinical Journal of Pain, Vol. 13, No. 4, 1997, pp. 285-286. doi:10.1097/00002508-199712000-00003

[73] Y. M. Chen, Y. L. Wei and G. L. Chen, "The Neuroanatomical Location and Percutaneous Cryotherapy of Lumbar Spinal Dorsal Ramu for Treatment of Low Back Pain," Chinese Orthopedic Journal, Vol. 1, No. 3, 1994, pp. 150-153.

[74] L. Q. Zhou, A. Miller, L. King and Z. Grunwald, "Spinal Dorsal Ramus Injections for Low Back Pain: A Retrospective Study," 1st Conference of the Asian Oceania Society of Physical and Rehabilitation Medicine, Nanjing, 16-19 May 2008, pp. 260-265.

[75] I. F. Lin, F. D. Chen, C. M. Huang, X. J. Tong and J. C. Bao, "Percutaneous Cryotherapy of Spinal Dorsal Ramus for Low Back Pain: 120 Cases," in Chinese, Journal of Medical Colleges of PLA, Vol. 1, 1994, pp. 61-62.

[76] A. M. Trescot, "Cryoanalgesia in Interventional Pain Management," Pain Physician, Vol. 6, No. 3, 2003, pp. 345360.

[77] L. A. Whitworth and C. A. Feler, "Application of Spinal Ablative Techniques for the Treatment of Benign Chronic Painful Conditions: History Methods, and Outcomes," Spine, Vol. 27, No. 22, 2002, pp. 2607-2613. doi:10.1097/00007632-200211150-00039

[78] J. Schofferman and G. Kine, "Effectiveness of Repeated Radiofrequency Neurotomy for Lumbar Facet Pain," Spine, Vol. 29, No. 21, 2004, pp. 2471-2473. doi:10.1097/01.brs.0000143170.47345.44

[79] C. A. Kornic, S. S. Kramarich and B. Sitzman, "Complications of Lumbar Facet Radiofrequency Denervation," Spine, Vol. 29, No. 12, 2004, pp. 1352-1354. doi:10.1097/01.BRS.0000128263.67291.A0

[80] P. Dreyfuss, A. Stout, C. Aprill, S. Pollei, B. Johnson and N. Bogduk, "The Significance of Multifidus Atrophy after Successful Radiofrequency Neurotomy for Low Back Pain," PM\&R, Vol. 1, No. 8, 2009, pp. 719-722. doi:10.1016/i.pmrj.2009.05.014 